\title{
Inflammatory lesions in the bone marrow of rheumatoid arthritis patients: a morphological perspective
}

\author{
Serena Bugatti*, Antonio Manzo, Roberto Caporali and Carlomaurizio Montecucco
}

\begin{abstract}
The synovial tissue stands at the epicenter of joint pathology in rheumatoid arthritis (RA). As a primary target of the disease, studies on the synovium have provided invaluable insights into the mechanisms involved in disease pathogenesis. Recent work has, however, revealed the importance of a previously unseen anatomic compartment in direct contact with the joint space, namely the subchondral bone marrow. Bone marrow edema (BME) visible on magnetic resonance imaging (MRI) is clinically meaningful in both early and late RA as it associates with future development of bone erosions and poor functional outcomes. Although the histopathologic correlates of MRI-based BME in early RA remain obscure, studies in advanced disease are consistent in describing lymphocytic inflammatory infiltrates within the subchondral marrow cavity of affected joints. In this review, we discuss the nature of bone marrow lesions in patients with RA, analyze their relationship with synovitis, and explore their potential contribution to the pathological processes of the disease.
\end{abstract}

Rheumatoid arthritis (RA) is traditionally regarded as an archetypal disease of the synovial tissue. The synovial membrane indeed undergoes early inflammatory changes, which include increased vascularity as well as intimal lining layer hyperplasia and accumulation of macrophages, plasma cells, T cells, B cells, dendritic cells, natural killer cells and mast cells in the sublining, among other changes [1]. Collectively, localization of inflammation to the synovium is primarily responsible for the dysregulated cellular and molecular mechanisms that

*Correspondence: serena.bugatti@unipv.it

Division and Laboratory of Rheumatology, University of Pavia School of Medicine, IRCCS Policlinico San Matteo Foundation; Piazzale Golgi, 2, 27100 Pavia, Italy ultimately lead to the typical signs and symptoms of RA, including joint pain, stiffness, swelling and structural changes. Although the pathogenic and clinical importance of synovitis is beyond question, it is becoming increasingly apparent that a 'synovio-centric' model of RA could be limiting. Indeed, other anatomic compartments appear to be involved at all stages of the disease. The most important example comes from the recognition that clinical arthritis and subclinical synovitis are anticipated by a pre-articular immunologic phase possibly developing in lymphoid tissues as well as in the lungs $[2,3]$. Full-blown joint disease itself spreads well beyond synovial tissue inflammation. Established arthritis can be characterized by the involvement of at least two other compartments that are in direct contact with the joint space. These include the draining lymph nodes (LNs) $[4,5]$ and, of special relevance, the subchondral bone marrow (BM) [6].

As dysregulated B cell responses are central pathogenic events in RA and B-cell autoreactivity originates, at least in part, from defective checkpoints within the BM (a primary lymphoid organ) [7], the role of this compartment in the immunopathogenesis of RA has attracted great attention over the years. Data supporting the existence of BM abnormalities were mainly derived from studies on marrow aspirates/biopsies from the sternum and the iliac crest, which are primary hematopoietic and immunologic sites in adult life. The role that the 'red marrow' might play in the immunologic disturbances of RA thus appears interesting but not completely unexpected. Less predictably, evidence has accumulated supporting the additional involvement of the BM adjacent to inflamed joints at peripheral sites. This is normally a fat-rich tissue ('yellow marrow') where hematopoiesis is not prominent. In $\mathrm{RA}$, the fat can be replaced by a vascularized, cell-rich inflammatory tissue. Combined with imaging data coming from magnetic resonance imaging (MRI) studies, histopathologic changes described within the subchondral BM have been postulated to be intimately involved in the pathological processes producing local inflammation and tissue 
remodeling in RA joints [6,8-10]. Here we will discuss the most relevant findings related to $\mathrm{BM}$ alterations in RA, focusing on their morphological characteristics and pathologic significance. In view of the clinical relevance of MRI findings, special emphasis is given to the subchondral BM.

\section{Histopathology of the bone marrow in rheumatoid arthritis}

\section{Systemic bone marrow}

Alongside its hematopoietic function and its role in the early selection of lymphocytes, the BM is an immune regulatory organ involved in migration, selective retainment and function of innate and adaptive immune cells [11]. A variety of morphological, immunophenotypic and functional abnormalities in BM cells in RA have been detected as a consequence of augmented local production of inflammatory cytokines and cell-cell interactions. Both myeloid and lymphoid lineage cells appear affected at some stage of the disease.

The absolute number of mononuclear cells was found markedly increased in iliac BM aspirates in RA patients compared to controls [12]. In addition, the spontaneous generation of CD14+ myeloid cells from BM progenitors in vitro as well as their maturation towards HLA-DR+ cells were accelerated in RA patients, indicating that alterations in the regenerative potential of the BM may occur $[13,14]$. The finding that levels of IL- 6 and IL-8 were markedly elevated in BM aspirates from RA patients (compared with controls) [15] is suggestive of ongoing pathology in the BM region. DNA microarray analysis also demonstrated that BM cells from RA patients have abnormal functional networks in immune response and cell cycle when compared to those from osteoarthritis patients, with overexpression of genes that take part in the antigen presentation pathway and interferon signaling [16]. Studies in experimental arthritis have confirmed a generalized pattern of red marrow conversion with enhanced myelopoiesis in conjunction with either increased IL-1 and IL-6 activity [17] or TNF overexpression [18]. Interestingly, high cellularity throughout the marrow seen on histologic examination in TNF-transgenic mice appears associated with a diffuse bone marrow edema (BME) pattern on MRI, distinct from subchondral BME coexisting with focal erosions [18]. Together with the observed alterations in the myeloid compartment, there is evidence that the BM environment in patients with RA may harbor aberrant B- and T-cell immune responses. Marrow plasmacytosis and hyperglobulinemia were already described in the 1950s in a number of independent studies (reviewed by Duthie and colleagues [19]). B cells derived from RA BM were later found to be capable of producing RA-associated autoantibodies, such as all rheumatoid factor (RF) isotypes
[20] as well as IgM anti-citrullinated peptide antibodies (ACPAs) [21]. Supporting a pathogenic role of T cells in this disease, an abnormal accumulation of HLA-DR+CD8+ and recently activated $\mathrm{CD} 3+\mathrm{CD} 4+\mathrm{T}$ lymphocytes has been detected in the iliac BM of RA patients (a site remote from inflamed joints) and also in femoral heads $[12,22,23]$.

From a morphological perspective, it is worth noting that, in chronic inflammatory conditions such as RA, the expanded lymphoid component of the BM may form follicle-like structures and undergo a localized process of ectopic lymphoid neogenesis. In a series of 65 marrow trephines, Engels and colleagues [24] reported morphologically benign lymphoid aggregates in 15 cases, 5 of which were diagnosed with RA or other autoimmune disorders. More recently, Kuca-Warnawin and colleagues [23] confirmed a follicular pattern of infiltrating lymphocytes in 9 of 15 BM trephine biopsy specimens from RA patients. Of these, five exhibited features of compartmentalized lymphoid follicles, with a core of CD20+ $\mathrm{B}$ cells surrounded by $\mathrm{CD} 4+\mathrm{T}$ cells and histologic evidence of germinal center (GC)-like structures. Functionality has yet to be demonstrated at these sites, but B-cell clonality was recognized in 9 of 15 patients (4 with an autoimmune disorder) in the series described by Engels and colleagues [24]. Local expression of the activation marker CD69 on follicular cells as well as increased levels of the T-cell growth factor IL-15 [23] are further clues that local immune cell activation may take place.

Collectively, the above-mentioned studies suggest that the systemic BM compartment may be involved in the pathogenesis of RA, though currently available data on its morphological alterations and functional properties have yet to be integrated into a coherent model of disease. Interest in the BM compartment as a potential source of biomarkers and information on drug mode of action has, however, been renewed following the successful introduction of B-cell-targeted therapies in RA. Compared to the almost complete suppression of $B$ cells in circulation, relatively high numbers of $B$ cells and $\mathrm{B}$-cell precursors persist in the $\mathrm{BM}$ after rituximab treatment [25-28]. The remaining B cells mostly consist of memory B cells [27]. Patients exhibiting a less complete $\mathrm{B}$-cell depletion and high proportion of more mature B cell precursors in their BM after rituximab therapy show a clinical response of relatively short duration [25]. Clinical response has also been shown to be preceded by a decrease in the number of memory B cells in the BM [28]. Disease relapse after rituximab could thus be attributable to several mechanisms related to BM partial depletion, involving B cell subsets at different stages of differentiation and activation. Incomplete suppression of $\mathrm{B}$ cells in the BM may be due to pharmacokinetic factors, 
local expression of anti-apoptotic molecules, patientrelated differences, or others. Further investigations on the mode of action of rituximab in the BM and in other compartments of the immune system are awaited in order to gain better understanding of the pathogenetic and clinical variability of RA.

\section{Subchondral bone marrow}

Inflammatory changes occurring within the juxta-articular $\mathrm{BM}$ in RA were reported over three decades ago. Barrie [29] observed cartilage damage, reparative changes and fibrovascular tissue within the subchondral marrow of surgically removed metatarsal and metacarpal heads in advanced RA. In similar surgical material, Wyllie [30] further described proliferation of fibroblasts, deposition of collagen, formation of thin-walled vascular channels, infiltrates of macrophages, lymphocytes and plasma cells. In RA knee joints, Bromley and colleagues [31] observed the presence of blood vessels and inflammatory cell infiltrates including mononuclear/macrophage cells in subchondral regions remote from the synovial pannuscartilage junction. These cellular aggregates were adjacent to erosions of the articular cartilage. In a similar study of RA subchondral bone removed from a patient undergoing knee replacement surgery, Watson and colleagues [32] described a local inflammatory reaction with nodular lymphocytic infiltrates accompanied by immunoglobulin deposits near areas of destroyed cartilage. More recently, in a series of 164 hip arthroplasties performed for various joint diseases, O'Connell and colleagues [33] found a total of ten cases (six with RA) with subchondral inflammation variably characterized by diffuse and nodular distribution. Altogether, descriptions of a subchondral inflammatory reaction in damaged RA joints gave rise at the end of the 1980s to the hypothesis of a 'bi-compartmental' model of RA, in which inflammation of the BM of affected joints actively contributed to the establishment of local damage [8,31].

The almost complete inaccessibility of the BM compartment to either clinical examination or traditional imaging (radiography) has contributed to a lack of interest in local marrow pathology until recent years. It has only been since the advent of MRI that the subchondral bone has gained recognition as a site of pivotal importance when considering the nature of the inflammatory process in RA. MRI-based BM involvement in the form of BME is a common feature in late and early RA, where it associates with disease activity and, most importantly, with future development of bone erosions and poor functional outcomes (for a review on BME in RA, see $[9,10]$ and the manuscript by FM McQueen in this edition of Arthritis Research and Therapy).

While the clinical importance of MRI-based BM involvement has been demonstrated consistently, its exact nature and pathologic significance remain largely obscure. Whilst the synovial membrane is accessible using minimally invasive techniques, which can be applied even in the earliest phases of the disease [34], histologic verification of the bone edema seen on MRI is virtually impossible in early disease because of difficulties in obtaining appropriate biopsy tissue. The few published studies comparing the histopathology of subchondral bone with MRI appearances include patients with longstanding disease undergoing major joint surgery, in which erosive and secondary degenerative changes could complicate the picture. Taking into account these limitations, Jimenez-Boj and colleagues [35] in 2007 significantly contributed to this field of research by providing the first description of the histologic correlates of BME. The authors had the chance to examine 12 small joints of the hand obtained from 3 RA patients scheduled for joint replacement surgery and undergoing MRI on the day before surgery. Disease duration was 8,14 and 24 years, respectively. Despite the limited number of patients, it was consistently shown that BME corresponded to regions in which the BM fat had been replaced by an inflammatory infiltrate rather than true edema. Such infiltrate was dense and highly vascularized in superficial regions of the marrow adjacent to synovial penetration through cortical bone (bone erosions), whilst was milder $(<50 \%$ infiltrates/tissue area) in more central areas. In the same year, McQueen and colleagues [36] independently confirmed the presence of osteitis in seven bone specimens with BME at MRI obtained from four different patients with longstanding disease. On immunohistochemical evaluation of these plus additional bone samples $(n=28)$ from 11 RA patients, the same authors later showed that marrow inflammatory lesions corresponding to BME were characterized by a variable proportion of macrophages, plasma cells, CD8+ T cells and B cells [37]. The nature and cellular composition of BM involvement in RA has been defined in detail by two further independent studies using modern immunohistochemical techniques $[38,39]$. Although direct comparison with MRI images was not available, our group could demonstrate that the marrow inflammatory infiltrate in both large and small joints of patients with long-standing RA was mainly organized into follicles of $B$ and $T$ lymphocytes (Figure 1) [38]. These structures, which were highly variable in size and density distribution among different bone samples, had acquired, in a proportion of cases, lymphoid-like morphological features, including a peripheral LN addressin-positive vascular apparatus, CD21+ follicular dendritic cell (FDC) networks and expression of the lymphoid chemokines CXCL13 and CCL21 [38]. Jimenez-Boj and colleagues [39] described a similar pattern, with preponderance of B cells within marrow aggregates. A more detailed analysis 

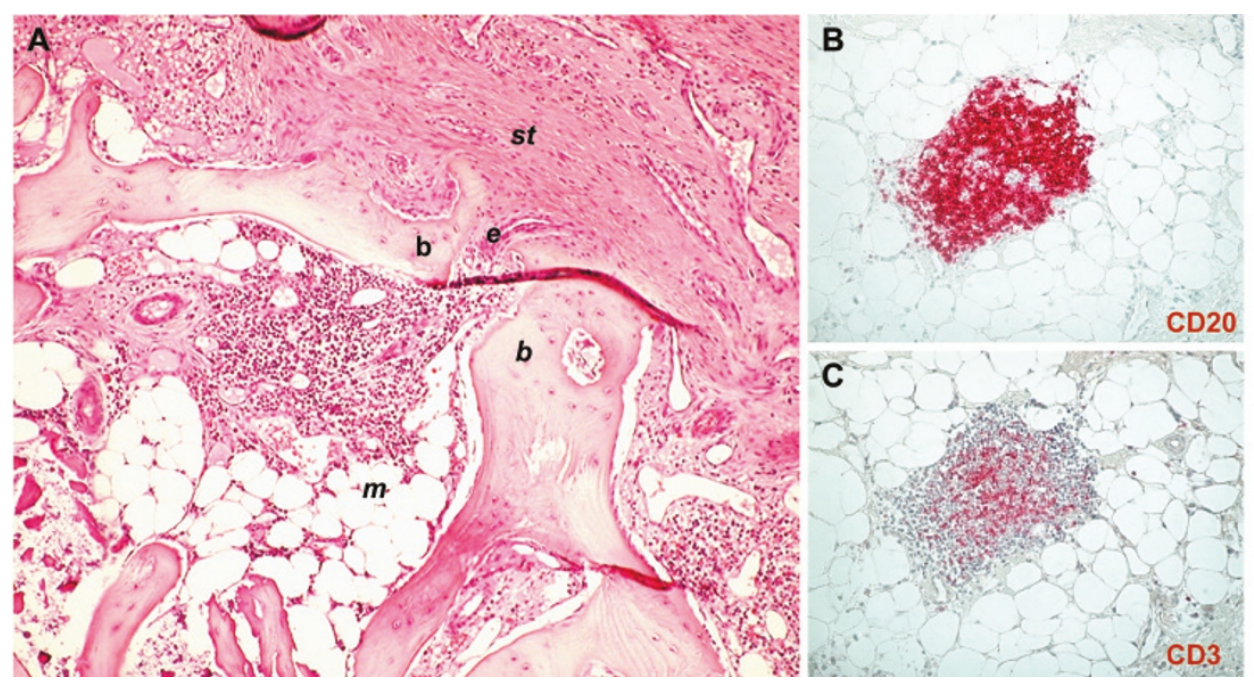

Figure 1. Subchondral bone marrow lymphocytic follicles in rheumatoid arthritis. A representative example of the inflammatory infiltrate in the subchondral bone marrow of a patient with rheumatoid arthritis undergoing joint replacement surgery of the hip. (A) Hematoxylin and eosin-stained section showing a mononuclear cell aggregate in the subchondral bone marrow adjacent to synovial tissue invasion into the marrow cavity through established cortical erosions. Note that the synovial tissue at the synovium-marrow boundary is mainly fibrous and acellular, whilst dense cellular infiltration can be observed within the marrow space. st, synovial tissue; e, erosion; b, bone; m, marrow. (B,C) Serial histologic sections of a mononuclear cell aggregate in the subchondral bone marrow stained for the B-cell marker CD20 (B) and the T-cell marker CD3 (C). Note the abundance of CD20 expression in the subchondral bone marrow aggregate. (A) Original magnification $\times 10$; $(\mathrm{B}, \mathrm{C})$ original magnification $\times 40$.

of B-cell markers revealed an abundance of CD27+ mature B cells. Plasma cells located at the periphery of marrow aggregates contributed $8 \pm 4 \%$ of total cells [39]. A follicular organization of the lymphocytic infiltrate with histologic evidence of GC-like structures has been recently confirmed in three out of six subchondral bone specimens obtained from hip replacement surgery in patients with advanced RA [23].

Although no direct comparison is available with the histologic pattern of BME in other joint diseases, some morphological peculiarities of RA osteitis could reflect disease-specific mechanisms. BME in the spondyloarthritides equally corresponds to a mononuclear infiltrate possibly organized into follicles. Here, however, $\mathrm{T}$ cells largely predominate [40-43], in keeping with the limited role attributable to $\mathrm{B}$ cells in these conditions [44]. On the other hand, the marrow inflammatory tissue in osteoarthritis is mainly fibrovascular with scarce cellular infiltration [45-48]. This pattern could result from biomechanical (excessive loading) rather than inflammatory alterations [49].

In summary, notwithstanding the relatively small case series analyzed and the unavailability of data on early arthritis, it appears indisputable that the subchondral aspect of the RA joint may harbor regions of bone inflammation (osteitis) dominated by lymphocytes. Whether this process is quantitatively or qualitatively comparable to synovial inflammation (synovitis) and to what extent it affects specific disease outcomes will be discussed in the next two paragraphs. Table 1 summarizes the main findings of modern studies addressing the histologic picture of subchondral BM involvement in RA.

\section{Relationship between subchondral bone marrow inflammation and synovitis}

\section{Morphological relationship}

A detailed description of the histopathology of the inflamed synovium in RA goes beyond the scope of this review. Some specific aspects of the lymphoid inflammatory infiltrate, however, deserve brief discussion in light of the similarities to BM features.

It has long been recognized that lymphocytes infiltrating the inflamed synovium may become organized into follicular clusters in a variable but yet considerable proportion of tissue specimens [4,50,51]. Although these structures frequently lack complex organizational features [52], some may acquire specific lymphoid-like aspects. These include the formation of high endothelial venules, the enrichment of $T$ and $B$ cells in partially separated areas, the differentiation of local stromal cells with development of FDC networks and vestiges of the fibroblastic reticular network, and the local synthesis of homeostatic chemokines $[4,52,53]$. Whether these structures may promote local immunological activity and to what extent they contribute to RA pathology are critical issues. The findings of Schröder and colleagues [54] are pertinent with respect to this. After microdissection of B lymphocytes from FDC-rich lymphoid aggregates within RA synovial membrane, they performed molecular analysis of the $\mathrm{V}$-gene repertoire. They found evidence 
Table 1. Main studies addressing the histopathologic picture of subchondral bone marrow involvement in rheumatoid arthritis

\begin{tabular}{|c|c|c|c|c|c|}
\hline & $\begin{array}{l}\text { Number } \\
\text { of samples }\end{array}$ & $\begin{array}{l}\text { Disease } \\
\text { duration* }\end{array}$ & Site of surgery & MRI & Main findings \\
\hline Jimenez-Boj et al. [39] & 12 (12 pts) & $18.9( \pm 2.8)$ & $\begin{array}{l}10 \text { small joints, } 1 \text { wrist, } \\
1 \text { large joint }\end{array}$ & - & $\begin{array}{l}\text { Lymphocytic aggregates with predominance } \\
\text { of B cells (immunohistochemistry) }\end{array}$ \\
\hline Bugatti et al. [38] & 8 (8 pts) & $12.5( \pm 8.8)$ & $\begin{array}{l}2 \text { small joints, } 1 \text { wrist, } \\
5 \text { large joints }\end{array}$ & - & Lymphocytic aggregates (immunohistochemistry) \\
\hline Kuca-Warnawin et al. [23] & 6 (6 pts) & - & 6 large joints & - & Lymphocytic aggregates (immunohistochemistry) \\
\hline Jimenez-Boj et al. [35] & 12 (3 pts) & $15.3( \pm 8.1)$ & 12 small joints & Available & $\begin{array}{l}\text { Infiltration of hematopoietic cells, lymphocytic } \\
\text { aggregates, blood vessels (histology) }\end{array}$ \\
\hline McQueen et al. [36] & 7 (4 pts) & $27( \pm 11.7)$ & 7 small joints & Available & $\begin{array}{l}\text { Lymphoplasmacytic infiltration, focal necrosis, } \\
\text { fibrosis (histology) }\end{array}$ \\
\hline Dalbeth et al. [37] & 28 (11 pts) & $21( \pm 9.6)$ & $\begin{array}{l}23 \text { small joints, } 2 \text { wrists, } \\
3 \text { ankles }\end{array}$ & Available & $\begin{array}{l}\text { Infiltration of macrophages, plasma cells, } \\
\text { CD8+T cells, B cells (immunohistochemistry) }\end{array}$ \\
\hline Total & 73 (44 pts) & & $\begin{array}{l}54 \text { small joints (hands/feet), } \\
7 \text { wrists/ankles, } 12 \text { large } \\
\text { joints (knee/hip) }\end{array}$ & & \\
\hline
\end{tabular}

${ }^{*}$ Data given as mean $( \pm S D)$ years. Pts, patients.

for an oligoclonal repertoire with highly mutated $\mathrm{V}$ regions, compatible with a local antigen-driven GC-like reaction [54]. Furthermore, a large amount of plasma cells infiltrating the synovial tissue appeared to be generated by locally activated B cells [55]. These findings are consistent with the observed local expression of AID (activation-induced cytidine deaminase), an enzyme critically involved in somatic hypermutation and classswitching of the immunoglobulin genes within conventional GCs of secondary lymphoid tissues [56]. Synovial lymphoid follicles may represent an histologic feature associated with disease severity and target organ damage [57]. Ectopic lymphoid aggregates are indeed associated with more severe synovial and systemic inflammation $[58,59]$ and B-cell-rich infiltrates appear a marker of erosive disease [60-62]. Whether these relationships are linked causally or represent bystander events remains unknown. Supporting a direct link between B-cell autoimmunity and tissue damage, human autoantibodies against citrullinated vimentin have been recently shown to induce osteoclastogenesis and bone loss [63].

Although studies directly comparing marrow and synovial follicles are limited [39], data presented herein indicate that the overall morphological picture mainly coincides. Slight differences in cellular composition may be related to higher proportions of $\mathrm{B}$ cells and plasma cells and less macrophages in subchondral BM aggregates [39]. Consistent with the considerable heterogeneity observed at the synovial tissue level [52], characteristics of the lymphoid-like features may vary considerably among different BM samples. Thus, subchondral BM CD21+ FDC networks and histological features of GClike structures have been described but appear rare $[23,32,38]$ or even absent [39]. Similarly, vascular addressins are found in a variable proportion of specimens
$[38,39]$. Other relevant aspects, such as the local organization of T-cell area fibroblastic reticular networks, have been assessed at the synovial tissue level [64] but their eventual correlates within the BM are so far unknown. Functionality at these sites has yet to be demonstrated. The possibility of a link between subchondral BM follicles and the pathological processes of the disease is suggested by the finding that these structures are more prominent in patients with large numbers of swollen joints, a high acute phase response and high titers of RF [39]. Histologically, enrichment in marrow follicles has been consistently observed in areas of cortical bone destruction $[38,39,57]$.

\section{Hierarchical relationship}

A critical aspect for our understanding of the actual significance of marrow pathology in RA is the identification of the hierarchical relationship between synovitis and subchondral osteitis. Two separate scenarios can theoretically be hypothesized: one is that RA is a disease starting in the synovial tissue, which then invades the subchondral bone cavity through established bone erosions; the other is that of a primary BM disease, which then spreads to the synovial membrane. In the absence of histopathologic data in the very early and possibly preclinical phases of the disease, both theories are based on assumptions rather than facts.

Analyses of tissue samples obtained from patients with long-standing erosive RA have consistently shown that marrow follicles are preferentially located in superficial areas of the subchondral bone at sites of synovial tissue penetration through cortical bone erosions (Figure 1A) $[38,39]$. Such a picture appears strongly evocative of an 'outside-in' model in which marrow inflammation originates from propagation of adjacent synovial 
inflammation. On the other hand, although no clues at present indicate that early osteitis morphologically corresponds to the osteitis of advanced disease, MRI studies in the earliest stages of RA reveal BM alterations before any obvious communication with the synovium is detectable [65]. Extensive BME has been also documented in patients with undifferentiated arthritis later developing RA [66] as well as in patients with ACPA-positive palindromic rheumatism, a proposed model of preclinical RA [67]. Histologically, mild inflammatory infiltrates have been described also in deeper areas of the subchondral bone remote from the synovial-marrow junction $[38,39]$. More intriguingly, lymphoid reactions occurring at the synovial-marrow boundary are conspicuous whilst the corresponding synovial tissue penetrating through cortical erosions is mainly fibrous [38]. Altogether, these data would suggest the autonomy (at least in part) of osteitis from synovitis. The picture is, however, further complicated by recent evidence demonstrating that the synovium and the BM can physiologically communicate through microscopic bone canals $(<0.5 \mathrm{~mm}$ in width or depth) visible using highresolution computed tomography [68]. These canals could allow the transduction of inflammation from the outside (synovium) to the inside (BM) and vice versa. Both routes are theoretically viable. In collagen-induced arthritis, mesenchymal cells originating from the juxtaarticular BM have been shown to travel to the synovium through enlarged bone canals in the pre-arthritic phase [69]. On the other hand, in the same experimental model, expression of inflammatory cytokines and osteoclastogenic factors has been almost exclusively detected at the synovial tissue level, suggesting that subchondral BM reactions are in fact driven by signals propagating from the synovium [70]. Exactly how the findings obtained in animal models fit into the spectrum of human RA awaits further definition.

The 'inside-out' concept may be more applicable in other forms of arthritis, such as the spondyloarthritides. In anterior spondylitis, inflammation dominates the BM in areas with no adjacent synovium [41,42]. In contrast, the centrality of synovitis in RA remains incontestable. Imaging and histologic studies have, however, added another layer of complexity to models of pathogenesis in the inflammatory arthritides, by demonstrating that joint inflammation is not exclusive to the synovial membrane but also extends to the neighboring BM.

\section{Are additional structures involved in the local inflammatory process of RA? The possible contribution of the draining lymph nodes}

As long as our perspective on joint inflammation in RA has expanded from the synovial compartment to the subchondral $\mathrm{BM}$, the draining $\mathrm{LN}$ has emerged as an additional player involved in multiple aspects of the disease. These include the generation of local immunological responses as well as the control of cell efflux from the joint.

LN involvement in experimental models appears early and possibly antedates clinical arthritis. An increase in the percentage of B lymphocytes as well as a high proliferation of CD8+ cells were observed in regional LNs in the latency period of adjuvant arthritis [71]. In the K/ BxN model of spontaneous autoimmunity, the LNs draining the distal joints were found to be essential for the amplification of the arthritogenic B-cell response [72]. Similarly, changes in the popliteal LN have been reported prior to disease onset in TNF-transgenic mice [73,74], with accumulation of CD23+CD21highCD1high B cells [75-77]. Such a cell population was recently shown to differentiate locally, to display an enhanced ability to capture and process antigens and to exhibit a GC phenotype during T-cell-dependent immune responses [78]. The specific relevance of these findings to autoimmune responses in RA is currently unknown. Also, early LN involvement in humans remains to be demonstrated. Former histologic studies on LN biopsies from different anatomic sites in established RA described follicular hyperplasia and interfollicular plasmacytosis [79] as well as increased GCs with high B-cell activity [80]. In RF and/or ACPA-positive individuals at risk of developing RA and in early arthritis patients, an increase of activated CD69+ cells and a significant change in the CD4/CD8 distribution was reported in inguinal LNs [81]. Ultrasound-guided biopsy of inguinal LNs appears feasible and safe [82] and promises to yield important information in the near future.

Alongside their potential role in modulating autoimmunity, the draining LNs may be also critically associated with the severity of joint involvement. Longitudinal studies in TNF-transgenic mice demonstrated a negative correlation between LN contrast enhancement and LN volume on MRI and local progression of synovitis, suggesting that reduced LN drainage capacity may determine worst arthritis outcomes [73,74]. A similar relationship between local disease activity in the joints and ultrasonographic signs of axillary LN involvement has been recently reported in humans [5]. Histologically, arthritic flares in experimental models are associated with ipsilateral LN collapse due to lymphatic obstruction and diminished lymphatic flow [77]. Accordingly, inhibition of lymphatic drainage increases the severity of joint inflammation in TNF-transgenic mice [75].

\section{Relationship between subchondral bone marrow inflammation and bone remodeling}

Clinically, BME on MRI is one of the strongest predictors of bone erosions in RA $[9,10,65]$. However, whether such 

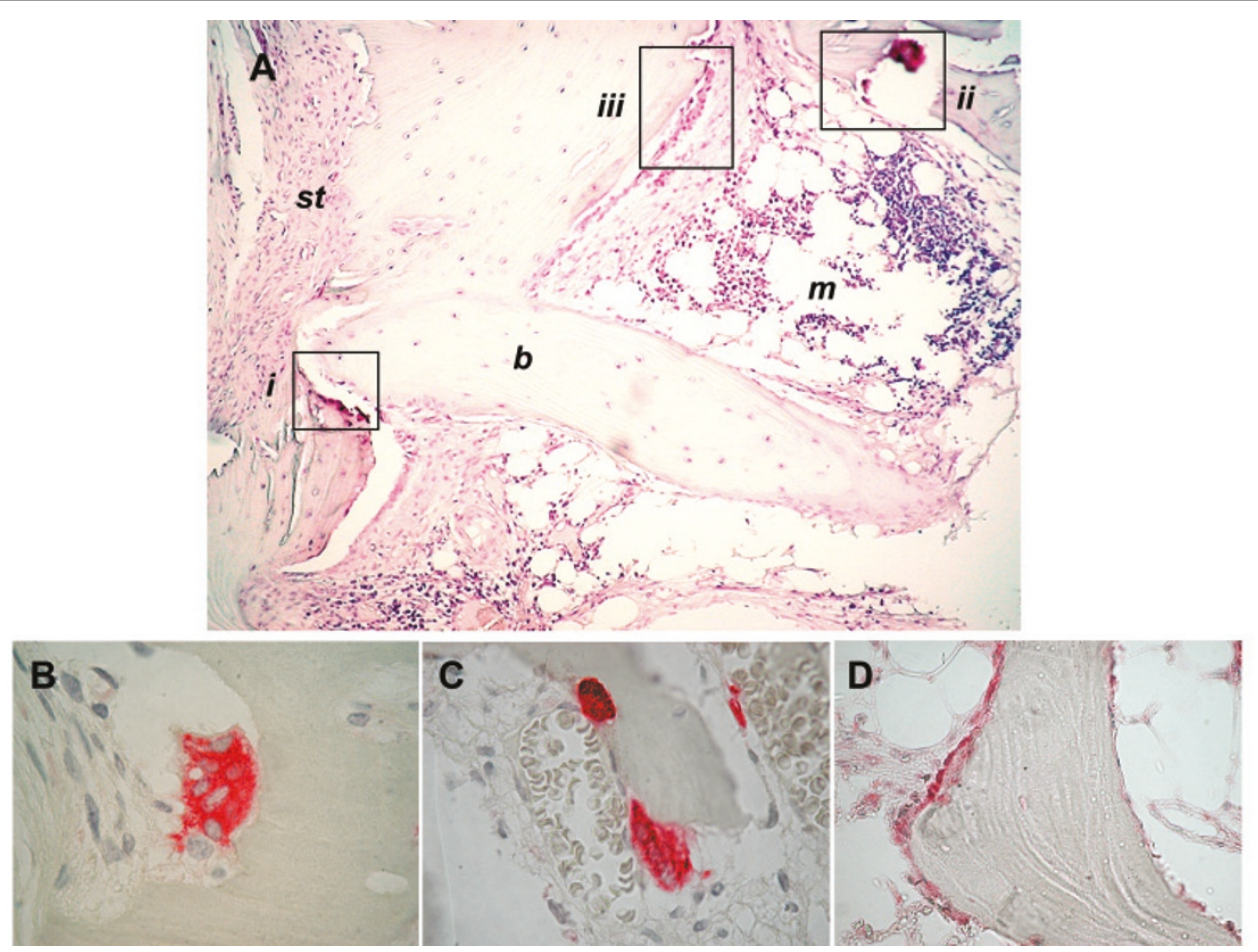

Figure 2. Bone cells in the synovial and subchondral compartment in rheumatoid arthritis. (A) Hematoxylin and eosin-stained section of a subchondral bone specimen with histologic evidence of erosions and intra-marrow inflammation. The different distribution of osteoclasts and osteoblasts is shown. Areas with osteoclast accumulation are visible on both the synovial (i) and the subchondral (ii) side of the joint. Osteoblasts and bone lining cells are instead located on the endosteal surface (iii). st, synovial tissue; b, bone; m, marrow. (B,C) Immunostainings for the osteoclast marker tartrate-resistant acid phosphatase (TRAP) showing TRAP-positive multinucleated osteoclasts resorbing bone from the synovium (B) as well as from the subchondral bone (C). (D) Immunostaning for parathytoid hormone receptor (PTH-R) showing PTH-R-positive cuboid osteoblasts and bone-lining cells in the subchondral compartment. (A) Original magnification $\times 10$; (B-D) original magnification $\times 100$.

an association implies a causative link remains to be determined.

Chondroclasts and osteoclasts were morphologically described in the subchondral bone of RA knee joints over 30 years ago [83]. More recently, using specific immunostaining we demonstrated tartrate-resistant acid phosphatase (TRAP)- and cathepsin K-positive multinucleated osteoclasts on the marrow side of RA samples, which were associated (in terms of density) with the extent of subchondral marrow inflammation [38]. Others have later extended these findings by providing evidence of local expression of molecules involved in osteoclastogenesis and tissue destruction, such as receptor activator of NF- $\mathrm{kB}$ ligand (RANKL), cathepsins and metalloproteinases $[37,84]$. Together with MRI studies, these data would suggest an active participation of the subchondral compartment to joint remodeling processes. RA erosions, however, anatomically and radiologically remain 'outside-in' processes. This pattern could be ascribed to differences in the local balance of erosive and reparative mechanisms between the synovial and the subchondral side of RA joints. Whilst bone-resorbing osteoclasts can be detected on both sides, bone-forming osteoblasts and osteoid deposition are recognized only on bone surfaces adjacent to the marrow (Figure 2), as suggested by studies in experimental arthritis and human RA $[38,39,85,86]$. The role of the BM in RA might thus not be entirely negative. Accordingly, it has been recently shown that repair of bone erosions in RA patients treated with TNF inhibitors, although rare, is based on bone apposition at the base of erosion and probably involves the BM [87].

\section{Conclusion}

RA remains a chronic autoimmune disease mainly involving the synovial tissue. However, evidence is mounting that the initiation and perpetuation of inflammation may involve additional anatomic compartments, especially at certain stages of the disease. Following the recognition that RA-specific autoantibodies may arise years before the onset of clinical disease [88] and that the production of autoantibodies may persist despite effective suppression of synovial inflammation [89], the question of the specific extra-synovial sites contributing to RA immunopathology is attracting increasing attention. In view of its role in the maintenance of B-cell 
central tolerance and as a survival niche for long-lived plasma cells, the systemic BM is a plausible candidate, although its involvement in the very early, pre-clinical phases of the disease remains speculative. Fascinating but still merely hypothetical is the role of secondary lymphoid organs, including LNs. Besides their potential role in systemic autoimmunity, the same compartments (BM and LNs) could be also involved in local pathology at the sites of joint inflammation. From this perspective, the subchondral BM of affected joints appears tightly linked to the processes of local inflammation and tissue remodeling, as suggested by (many) imaging studies and (few) histopathologic data. Analogous evidence is emerging for the draining LNs, whose drainage capacity appears inversely related to local arthritis severity in experimental models.

We have just started unraveling the mystery of a 'multicompartmental' model of RA, but preliminary results encourage further research aimed at identifying novel pathogenic and clinical targets of the disease that may go beyond the well established synovial tissue immunopathologic environment.

This article is part of the series on Is rheumatoid arthritis a bone marrow disease? Other articles in this series can be found at http://arthritis-research.com/series/marrow

\section{Abbreviations}

$\mathrm{ACPA}$, anti-citrullinated protein antibody; $\mathrm{BM}$, bone marrow; $\mathrm{BME}$, bone marrow edema; FDC, follicular dendritic cell; GC, germinal center; IL, interleukin; LN, lymph node; MRI, magnetic resonance imaging; RA, rheumatoid arthritis; RF, rheumatoid factor; TNF, tumor necrosis factor; TRAP, tartrate resistant acid phosphatase.

\section{Competing interests}

The authors declare that they have no competing interests.

\section{Acknowledgements}

This study was supported in part by funding from the Italian Ministry of Health (grant 058/GR-2009-1608032 to AM)

Published: 27 December 2012

\section{References}

1. Hitchon CA, El-Gabalawy HS: The synovium in rheumatoid arthritis. Open Rheumatol J 2011, 5:107-114.

2. Klareskog L, Rönnelid J, Lundberg K, Padyukov L, Alfredsson L: Immunity to citrullinated proteins in rheumatoid arthritis. Annu Rev Immunol 2008, 26:651-675

3. van de Sande MG, de Hair MJ, van der Leij C, Klarenbeek PL, Bos WH, Smith MD, Maas M, de Vries N, van Schaardenburg D, Dijkmans BA, Gerlag DM, Tak PP: Different stages of rheumatoid arthritis: features of the synovium in the preclinical phase. Ann Rheum Dis 2011, 70:772-777.

4. Manzo A, Bombardieri M, Humby F, Pitzalis C: Secondary and ectopic lymphoid tissue responses in rheumatoid arthritis: from inflammation to autoimmunity and tissue damage/remodeling. Immuno/ Rev 2010, 233:267-285.

5. Manzo A, Caporali R, Vitolo B, Alessi S, Benaglio F, Todoerti M, Bugatti S, Calliada F, Montecucco C: Subclinical remodelling of draining lymph node structure in early and established rheumatoid arthritis assessed by power Doppler ultrasonography. Rheumatology 2011, 50:1395-1400.

6. Schett G, Firestein GS: Mr Outside and Mr Inside: classic and alternative views on the pathogenesis of rheumatoid arthritis. Ann Rheum Dis 2010 69:787-789.
7. Samuels J, Ng YS, Coupillaud C, Paget D, Meffre E: Impaired early B cell tolerance in patients with rheumatoid arthritis. J Exp Med 2005, 201:1659-1667.

8. Fujii K, Tsuji M, Tajima M: Rheumatoid arthritis: a synovial disease? Ann Rheum Dis 1999, 58:727-730

9. McQueen FM: A vital clue to deciphering bone pathology: MRI bone oedema in rheumatoid arthritis and osteoarthritis. Ann Rheum Dis 2007, 66:1549-1552.

10. Schett G: Bone marrow edema. Ann N Y Acad Sci 2009, 1154:35-40.

11. Woodland DL, Blackman MA: Immunity: it's in our bones. Immunity 2005, 22:143-144.

12. Tomita T, Kashiwagi N, Shimaoka Y, Ikawa T, Tanabe M, Nakagawa S, Kawamura S, Denno K, Owaki H, Ochi T: Phenotypic characteristics of bone marrow cells in patients with rheumatoid arthritis. J Rheumato/ 1994, 21:1608-1614.

13. Tomita T, Shimaoka Y, Kashiwagi N, Hashimoto H, Kawamura S, Lee SB, Nakagawa S, Shiho O, Hayashida K, Ochi T: Enhanced expression of CD14 antigen on myeloid lineage cells derived from the bone marrow of patients with severe rheumatoid arthritis. J Rheumatol 1997, 24:465-469.

14. Hirohata S, Yanagida T, Itoh K, Nakamura H, Yoshino S, Tomita T, Ochi T: Accelerated generation of CD14+ monocyte-lineage cells from the bone marrow of rheumatoid arthritis patients. Arthritis Rheum 1996, 39:836-843.

15. Tanabe M, Ochi T, Tomita T, Suzuki R, Sakata T, Shimaoka Y, Nakagawa S, Ono K: Remarkable elevation of interleukin 6 and interleukin 8 levels in the bone marrow serum of patients with rheumatoid arthritis. J Rheumatol 1994, 21:830-835.

16. Lee HM, Sugino H, Aoki C, Shimaoka Y, Suzuki R, Ochi K, Ochi T, Nishimoto N: Abnormal networks of immune response-related molecules in bone marrow cells from patients with rheumatoid arthritis as revealed by DNA microarray analysis. Arthritis Res Ther 2011, 13:R89.

17. Hayashida K, Ochi T, Fujimoto M, Owaki H, Shimaoka Y, Ono K, Matsumoto K: Bone marrow changes in adjuvant-induced and collagen-induced arthritis. Interleukin- 1 and interleukin- 6 activity and abnormal myelopoiesis. Arthritis Rheum 1992, 35:241-245.

18. Proulx ST, Kwok E, You Z, Papuga MO, Beck CA, Shealy DJ, Calvi LM, Ritchlin $C T$, Awad HA, Boyce BF, Xing L, Schwarz EM: Elucidating bone marrow edema and myelopoiesis in murine arthritis using contrast-enhanced magnetic resonance imaging. Arthritis Rheum 2008, 58:2019-2029.

19. Duthie JJ, Gardner DL, Richmond J, Roy LM: Nature of anaemia in rheumatoid arthritis. III. Changes in the bone marrow and their relation to other features of the disease. Ann Rheum Dis 1956, 15:217-226.

20. Otten HG, Daha MR, Dolhain RJ, de Rooy HH, Breedveld FC: Rheumatoid factor production by mononuclear cells derived from different sites of patients with rheumatoid arthritis. Clin Exp Immunol 1993, 94:236-240.

21. Reparon-Schuijt CC, van Esch WJ, van Kooten C, Schellekens GA, de Jong BA, van Venrooij WJ, Breedveld FC, Verweij CL: Secretion of anti-citrullinecontaining peptide antibody by $B$ lymphocytes in rheumatoid arthritis. Arthritis Rheum 2001, 44:41-47.

22. Doita M, Maeda S, Kawai K, Hirohata K, Sugiyama T: Analysis of lymphocyte subsets of bone marrow in patients with rheumatoid arthritis by two colour immunofluorescence and flow cytometry. Ann Rheum Dis 1990 49:168-171.

23. Kuca-Warnawin E, Burakowski T, Kurowska W, Prochorec-Sobieszek M, Radzikowska A, Chorazy-Massalska M, Maldyk P, Kontny E, Maslinski W: Elevated number of recently activated T cells in bone marrow of patients with rheumatoid arthritis: a role for interleukin 15? Ann Rheum Dis 2011 70:227-233.

24. Engels K, Oeschger S, Hansmann ML, Hillebrand M, Kriener S: Bone marrow trephines containing lymphoid aggregates from patients with rheumatoid and other autoimmune disorders frequently show clonal B-cell infiltrates. Hum Pathol 2007, 38:1402-1411.

25. Leandro MJ, Cooper N, Cambridge G, Ehrenstein MR, Edwards JC: Bone marrow B-lineage cells in patients with rheumatoid arthritis following rituximab therapy. Rheumatology 2007, 46:29-36.

26. Teng YK, Levarht EW, Hashemi M, Bajema IM, Toes RE, Huizinga TW, van Laar $\mathrm{JM}$ : Immunohistochemical analysis as a means to predict responsiveness to rituximab treatment. Arthritis Rheum 2007, 56:3909-3918.

27. Rehnberg M, Amu S, Tarkowski A, Bokarewa MI, Brisslert M: Short- and longterm effects of anti-CD20 treatment on B cell ontogeny in bone marrow of patients with rheumatoid arthritis. Arthritis Res Ther 2009, 11:R123.

28. Nakou M, Katsikas G, Sidiropoulos P, Bertsias G, Papadimitraki E, Raptopoulou 
A, Koutala H, Papadaki HA, Kritikos H, Boumpas DT: Rituximab therapy reduces activated $B$ cells in both the peripheral blood and bone marrow of patients with rheumatoid arthritis: depletion of memory B cells correlates with clinical response. Arthritis Res Ther 2009, 11:R131.

29. Barrie HJ: Histologic changes in rheumatoid disease of the metacarpal and metatarsal heads as seen in surgical material. $J$ Rheumatol 1981, 8:246-257.

30. Wyllie JC: Histopathology of the subchondral bone lesion in rheumatoid arthritis. J Rheumato/ Supp/ 1983, 11:26-28.

31. Bromley M, Bertfield H, Evanson JM, Woolley DE: Bidirectional erosion of cartilage in the rheumatoid knee joint. Ann Rheum Dis 1985, 44:676-681.

32. Watson WC, Tooms RE, Carnesale PG, Dutkowsky JP: A case of germinal center formation by CD45RO T and CD20 B lymphocytes in rheumatoid arthritic subchondral bone: proposal for a two-compartment model of immune-mediated disease with implications for immunotherapeutic strategies. Clin Immunol Immunopathol 1994, 73:27-37.

33. O'Connell JX, Nielsen GP, Rosenberg AE: Subchondral acute inflammation in severe arthritis: a sterile osteomyelitis? Am J Surg Pathol 1999, 23:192-197.

34. Scirè CA, Epis O, Codullo V, Humby F, Morbini P, Manzo A, Caporali R, Pitzalis C, Montecucco C: Immunohistological assessment of the synovial tissue in small joints in rheumatoid arthritis: validation of a minimally invasive ultrasound-guided synovial biopsy procedure. Arthritis Res Ther 2007, 9:R101.

35. Jimenez-Boj E, Nöbauer-Huhmann I, Hanslik-Schnabel B, Dorotka R, Wanivenhaus AH, Kainberger F, Trattnig S, Axmann R, Tsuji W, Hermann S, Smolen J, Schett G: Bone erosions and bone marrow edema as defined by magnetic resonance imaging reflect true bone marrow inflammation in rheumatoid arthritis. Arthritis Rheum 2007, 56:1118-1124.

36. McQueen FM, Gao A, Ostergaard M, King A, Shalley G, Robinson E, Doyle A, Clark B, Dalbeth N: High-grade MRI bone oedema is common within the surgical field in rheumatoid arthritis patients undergoing joint replacement and is associated with osteitis in subchondral bone. Ann Rheum Dis 2007, 66:1581-1587.

37. Dalbeth N, Smith T, Gray S, Doyle A, Antill P, Lobo M, Robinson E, King A, Cornish J, Shalley G, Gao A, McQueen FM: Cellular characterisation of magnetic resonance imaging bone oedema in rheumatoid arthritis; implications for pathogenesis of erosive disease. Ann Rheum Dis 2009, 68:279-282.

38. Bugatti S, Caporali R, Manzo A, Vitolo B, Pitzalis C, Montecucco C Involvement of subchondral bone marrow in rheumatoid arthritis: lymphoid neogenesis and in situ relationship to subchondral bone marrow osteoclast recruitment. Arthritis Rheum 2005, 52:3448-3459.

39. Jimenez-Boj E, Redlich K, Türk B, Hanslik-Schnabel B, Wanivenhaus A, Chott A, Smolen JS, Schett G: Interaction between synovial inflammatory tissue and bone marrow in rheumatoid arthritis. J Immunol 2005, 175:2579-2588.

40. Bollow M, Fischer T, Reisshauer H, Backhaus M, Sieper J, Hamm B, Braun J: Quantitative analyses of sacroiliac biopsies in spondyloarthropathies: T cells and macrophages predominate in early and active sacroiliitis- cellularity correlates with the degree of enhancement detected by magnetic resonance imaging. Ann Rheum Dis 2000, 59:135-140.

41. Appel H, Loddenkemper C, Grozdanovic Z, Ebhardt H, Dreimann M, Hempfing A, Stein H, Metz-Stavenhagen P, Rudwaleit M, Sieper J: Correlation of histopathological findings and magnetic resonance imaging in the spine of patients with ankylosing spondylitis. Arthritis Res Ther 2006, 8:R143.

42. Appel H, Kuhne M, Spiekermann S, Ebhardt H, Grozdanovic Z, Köhler D, Dreimann M, Hempfing A, Rudwaleit M, Stein H, Metz-Stavenhagen P, Sieper J, Loddenkemper C: Immunohistologic analysis of zygapophyseal joints in patients with ankylosing spondylitis. Arthritis Rheum 2006, 54:2845-2851.

43. Appel H, Kuhne M, Spiekermann S, Köhler D, Zacher J, Stein H, Sieper J, Loddenkemper C: Immunohistochemical analysis of hip arthritis in ankylosing spondylitis: evaluation of the bone-cartilage interface and subchondral bone marrow. Arthritis Rheum 2006, 54:1805-1813.

44. Baeten D, Kruithof E, Breban M, Tak PP: Spondylarthritis in the absence of B lymphocytes. Arthritis Rheum 2008, 58:730-733.

45. Zanetti M, Bruder E, Romero J, Hodler J: Bone marrow edema pattern in osteoarthritic knees: correlation between MR imaging and histologic findings. Radiology 2000, 215:835-840.

46. Saadat E, Jobke B, Chu B, Lu Y, Cheng J, Li X, Ries MD, Majumdar S, Link TM: Diagnostic performance of in vivo 3-T MRI for articular cartilage abnormalities in human osteoarthritic knees using histology as standard of reference. Eur Radiol 2008, 18:2292-22302.

47. Taljanovic MS, Graham AR, Benjamin JB, Gmitro AF, Krupinski EA, Schwartz SA,
Hunter TB, Resnick DL: Bone marrow edema pattern in advanced hip osteoarthritis: quantitative assessment with magnetic resonance imaging and correlation with clinical examination, radiographic findings, and histopathology. Skeletal Radiol 2008, 37:423-431.

48. Leydet-Quilici H, Le Corroller T, Bouvier C, Giorgi R, Argenson JN, Champsaur P, Pham T, de Paula AM, Lafforgue P: Advanced hip osteoarthritis: magnetic resonance imaging aspects and histopathology correlations. Osteoarthritis Cartilage 2010, 18:1429-1435.

49. Sun HB: Mechanical loading, cartilage degradation, and arthritis. Ann NY Acad Sci 2010, 1211:37-50.

50. Weyand $C M$, Goronzy J: Ectopic germinal center formation in rheumatoid synovitis. Ann N Y Acad Sci 2003, 987:140-149.

51. Bugatti S, Manzo A, Bombardieri M, Vitolo B, Humby F, Kelly S, Montecucco C, Pitzalis C: Synovial tissue heterogeneity and peripheral blood biomarkers. Curr Rheumatol Rep 2011, 13:440-448.

52. Manzo A, Paoletti S, Carulli M, Blades MC, Barone F, Yanni G, Fitzgerald O, Bresnihan B, Caporali R, Montecucco C, Uguccioni M, Pitzalis C: Systematic microanatomical analysis of CXCL13 and CCL21 in situ production and progressive lymphoid organization in rheumatoid synovitis. Eur I Immunol 2005, 35:1347-1359.

53. Corsiero E, Bombardieri M, Manzo A, Bugatti S, Uguccioni M, Pitzalis C: Role of lymphoid chemokines in the development of functional ectopic lymphoid structures in rheumatic autoimmune diseases. Immunol Lett 2012, 145:62-67.

54. Schröder AE, Greiner A, Seyfert C, Berek C: Differentiation of B cells in the nonlymphoid tissue of the synovial membrane of patients with rheumatoid arthritis. Proc Natl Acad Sci U S A 1996, 93:221-225.

55. Scheel T, Gursche A, Zacher J, Häupl T, Berek C: V-region gene analysis of locally defined synovial $B$ and plasma cells reveals selected $B$ cell expansion and accumulation of plasma cell clones in rheumatoid arthritis. Arthritis Rheum 2011, 63:63-72.

56. Humby F, Bombardieri M, Manzo A, Kelly S, Blades MC, Kirkham B, Spencer J, Pitzalis $C$ : Ectopic lymphoid structures support ongoing production of class-switched autoantibodies in rheumatoid synovium. PLoS Med 2009, 6:e1.

57. McQueen F, Elliott B: B cell lymphoproliferation and organ-directed selfrecognition to explain autoimmunity: back to the past. Med Hypotheses 2010, 75:328-333.

58. Thurlings RM, Wijbrandts CA, Mebius RE, Cantaert T, Dinant HJ, van der PouwKraan TC, Verweij CL, Baeten D, Tak PP: Synovial lymphoid neogenesis does not define a specific clinical rheumatoid arthritis phenotype. Arthritis Rheum 2008, 58:1582-1589

59. Cantaert T, Kolln J, Timmer T, van der Pouw Kraan TC, Vandooren B, Thurlings RM, Cañete JD, Catrina Al, Out T, Verweij CL, Zhang Y, Tak PP, Baeten D: B lymphocyte autoimmunity in rheumatoid synovitis is independent of ectopic lymphoid neogenesis. J Immunol 2008, 181:785-794.

60. Bugatti S, Manzo A, Vitolo B, Fusetti C, Humby F, Caporali R, Pitzalis C, Montecucco C: B cell distribution and activation-induced cytidine deaminase expression in rheumatoid synovitis: clinical and bio-molecular correlates. Ann Rheum Dis 2011, 70 (Suppl 2):A55.

61. Mo YQ, Dai L, Zheng DH, Zhu LJ, Wei XN, Pessler F, Shen J, Zhang BY: Synovial infiltration with CD79a-positive B cells, but not other B cell lineage markers, correlates with joint destruction in rheumatoid arthritis. J Rheumatol 2011, 38:2301-2308.

62. Lanfant-Weybel K, Michot C, Daveau R, Milliez PY, Auquit-Auckbur L, Fardellone P, Brazier M, Mejjad O, Daragon A, Krzanowska K, Jouen F, Tron F, Le Loarer F, Le Loët X, Vittecog O: Synovium CD20 expression is a potential new predictor of bone erosion progression in very-early arthritis treated by sequential DMARDs monotherapy - A pilot study from the VErA cohort Joint Bone Spine 2012, 79:574-580.

63. Harre U, Georgess D, Bang H, Bozec A, Axmann R, Ossipova E, Jakobsson PJ, Baum W, Nimmerjahn F, Szarka E, Sarmay G, Krumbholz G, Neumann E, Toes R, Scherer HU, Catrina Al, Klareskog L, Jurdic P, Schett G: Induction of osteoclastogenesis and bone loss by human autoantibodies against citrullinated vimentin. J Clin Invest 2012, 122:1791-1802.

64. Manzo A, Bugatti S, Caporali R, Prevo R, Jackson DG, Uguccioni M, Buckley CD, Montecucco C, Pitzalis C: CCL21 expression pattern of human secondary lymphoid organ stroma is conserved in inflammatory lesions with lymphoid neogenesis. Am J Pathol 2007, 171:1549-1562

65. Haavardsholm EA, Bøyesen P, Østergaard M, Schildvold A, Kvien TK: Magnetic resonance imaging findings in 84 patients with early rheumatoid arthritis: 
bone marrow oedema predicts erosive progression. Ann Rheum Dis 2008, 67:794-800.

66. Duer-Jensen A, Hørslev-Petersen K, Hetland ML, Bak L, Ejbjerg BJ, Hansen MS, Johansen JS, Lindegaard HM, Vinterberg H, Møller JM, Østergaard M: Bone edema on magnetic resonance imaging is an independent predictor of rheumatoid arthritis development in patients with early undifferentiated arthritis. Arthritis Rheum 2011, 63:2192-2202.

67. Bugatti S, Caporali R, Manzo A, Sakellariou G, Rossi S, Montecucco C: Ultrasonographic and MRI characterisation of the palindromic phase of rheumatoid arthritis. Ann Rheum Dis 2012, 71:625-626.

68. Stach CM, Bäuerle M, Englbrecht M, Kronke G, Engelke K, Manger B, Schett G: Periarticular bone structure in rheumatoid arthritis patients and healthy individuals assessed by high-resolution computed tomography. Arthritis Rheum 2010, 62:330-339.

69. Marinova-Mutafchieva L, Williams RO, Funa K, Maini RN, Zvaifler NJ: Inflammation is preceded by tumor necrosis factor-dependent infiltration of mesenchymal cells in experimental arthritis. Arthritis Rheum 2002, 46:507-513.

70. Kishimoto Y, Fukumoto S, Nishihara S, Mizumura H, Hirai K, Teshima R: Gene expression relevant to osteoclastogenesis in the synovium and bone marrow of mature rats with collagen-induced arthritis. Rheumatology 2004, 43:1496-1503.

71. Rodríguez-Palmero M, Pelegrí C, Ferri MJ, Castell M, Franch A, Castellote C: Alterations of lymphocyte populations in lymph nodes but not in spleen during the latency period of adjuvant arthritis. Inflammation 1999, 23:153-165

72. Mandik-Nayak L, Wipke BT, Shih FF, Unanue ER, Allen PM: Despite ubiquitous autoantigen expression, arthritogenic autoantibody response initiates in the local lymph node. Proc Natl Acad Sci U S A 2002, 99:14368-14373.

73. Proulx ST, Kwok E, You Z, Beck CA, Shealy DJ, Ritchlin CT, Boyce BF, Xing L, Schwarz EM: MRI and quantification of draining lymph node function in inflammatory arthritis. Ann N Y Acad Sci 2007, 1117:106-123.

74. Proulx ST, Kwok E, You Z, Papuga MO, Beck CA, Shealy DJ, Ritchlin CT, Awad $H A$, Boyce BF, Xing L, Schwarz EM: Longitudinal assessment of synovial, lymph node, and bone volumes in inflammatory arthritis in mice by in vivo magnetic resonance imaging and microfocal computed tomography. Arthritis Rheum 2007, 56:4024-4037.

75. Guo R, Zhou Q, Proulx ST, Wood R, Ji RC, Ritchlin CT, Pytowski B, Zhu Z, Wang YJ, Schwarz EM, Xing L: Inhibition of lymphangiogenesis and lymphatic drainage via vascular endothelial growth factor receptor 3 blockade increases the severity of inflammation in a mouse model of chronic inflammatory arthritis. Arthritis Rheum 2009, 60:2666-2676.

76. Li J, Kuzin I, Moshkani S, Proulx ST, Xing L, Skrombolas D, Dunn R, Sanz I, Schwarz EM, Bottaro A: Expanded CD23(+)/CD21(hi) B cells in inflamed lymph nodes are associated with the onset of inflammatory-erosive arthritis in TNF-transgenic mice and are targets of anti-CD20 therapy. J Immunol 2010, 184:6142-6150.

77. Li J, Zhou Q, Wood RW, Kuzin I, Bottaro A, Ritchlin CT, Xing L, Schwarz EM: CD23(+)/CD21(hi) B-cell translocation and ipsilateral lymph node collapse is associated with asymmetric arthritic flare in TNF-Tg mice. Arthritis Res Ther 2011, 13:R138.
78. Moshkani S, Kuzin II, Adewale F, Jansson J, Sanz I, Schwarz EM, Bottaro A: CD23+ CD21 (high) CD1d(high) B cells in inflamed lymph nodes are a locally differentiated population with increased antigen capture and activation potential. J Immunol 2012, 188:5944-5953.

79. Nosanchuk JS, Schnitzer B: Follicular hyperplasia in lymph nodes from patients with rheumatoid arthritis. A clinicopathologic study. Cancer 1969, 24:243-254.

80. Willkens RF, Roth GF, Husby G, Williams RC Jr: Immunocytological studies of lymph nodes in rheumatoid arthritis and malignant lymphoma. Ann Rheum Dis 1980, 39:147-151.

81. van Baarsen LGM, de Hair MJH, Ramwadhdoebe TH, van de Sande M, Zijlstra IJAJ, Maas M, Gerlag DM, Tak PP: Investigating the cellular composition of lymph nodes in preclinical and early inflammatory arthritis: a feasibility study. Ann Rheum Dis 2012, 71 Suppl 1:A20.

82. de Hair MJ, Zijlstra IA, Boumans MJ, van de Sande MG, Maas M, Gerlag DM, Tak PP: Hunting for the pathogenesis of rheumatoid arthritis: core-needle biopsy of inguinal lymph nodes as a new research tool. Ann Rheum Dis 2012, 71:1911-1912.

83. Bromley M, Woolley DE: Chondroclasts and osteoclasts at subchondral sites of erosion in the rheumatoid joint. Arthritis Rheum 1984, 27:968-975.

84. Kaneko M, Tomita T, Nakase T, Ohsawa Y, Seki H, Takeuchi E, Takano H, Shi K, Takahi K, Kominami E, Uchiyama Y, Yoshikawa H, Ochi T: Expression of proteinases and inflammatory cytokines in subchondral bone regions in the destructive joint of rheumatoid arthritis. Rheumatology 2001, 40:247-255.

85. Görtz B, Hayer S, Redlich K, Zwerina J, Tohidast-Akrad M, Tuerk B, Hartmann C, Kollias G, Steiner G, Smolen JS, Schett G: Arthritis induces lymphocytic bone marrow inflammation and endosteal bone formation. J Bone Miner Res 2004, 19:990-998.

86. Walsh NC, Reinwald S, Manning CA, Condon KW, Iwata K, Burr DB, Gravallese EM: Osteoblast function is compromised at sites of focal bone erosion in inflammatory arthritis. J Bone Miner Res 2009, 24:1572-1585.

87. Finzel S, Rech J, Schmidt S, Engelke K, Englbrecht M, Stach C, Schett G: Repair of bone erosions in rheumatoid arthritis treated with tumour necrosis factor inhibitors is based on bone apposition at the base of the erosion. Ann Rheum Dis 2011, 70:1587-1593.

88. Nielen MM, van Schaardenburg D, Reesink HW, van de Stadt RJ, van der Horst-Bruinsma IE, de Koning MH, Habibuw MR, Vandenbroucke JP, Dijkmans BA: Specific autoantibodies precede the symptoms of rheumatoid arthritis: a study of serial measurements in blood donors. Arthritis Rheum 2004, 50:380-386.

89. Bobbio-Pallavicini F, Caporali R, Bugatti S, Montecucco C: What can we learn from treatment-induced changes in rheumatoid factor and anticitrullinated peptide antibodies? J Rheumatol 2008, 35:1903-1905.

doi:10.1186/ar4115

Cite this article as: Bugatti S, et al.: Inflammatory lesions in the bone marrow of rheumatoid arthritis patients: a morphological perspective. Arthritis Research \& Therapy 2012, 14:229. 